\title{
Amyotrophic lateral sclerosis, dysarthria, and language disorders - type of research and approaches in different areas: an integrative literature review
}

\section{Lavoisier Leite Neto ${ }^{1}$} https://orcid.org/0000-0002-7796-5973

Marcondes Cavalcante França Júnior ${ }^{2}$

https://orcid.org/0000-0003-0898-2419

Regina Yu Shon Chun ${ }^{1}$

https://orcid.org/0000-0002-5305-7081
Universidade Estadual de Campinas - UNICAMP, Faculdade de Ciências Médicas, Departamento de Desenvolvimento Humano e Reabilitação, Programa Saúde, Interdisciplinaridade e Reabilitação, Campinas, São Paulo, Brasil.

2 Universidade Estadual de Campinas - UNICAMP, Faculdade de Ciências Médicas, Departamento de Neurologia, Campinas, São Paulo, Brasil.

Conflict of interests: Nonexistent

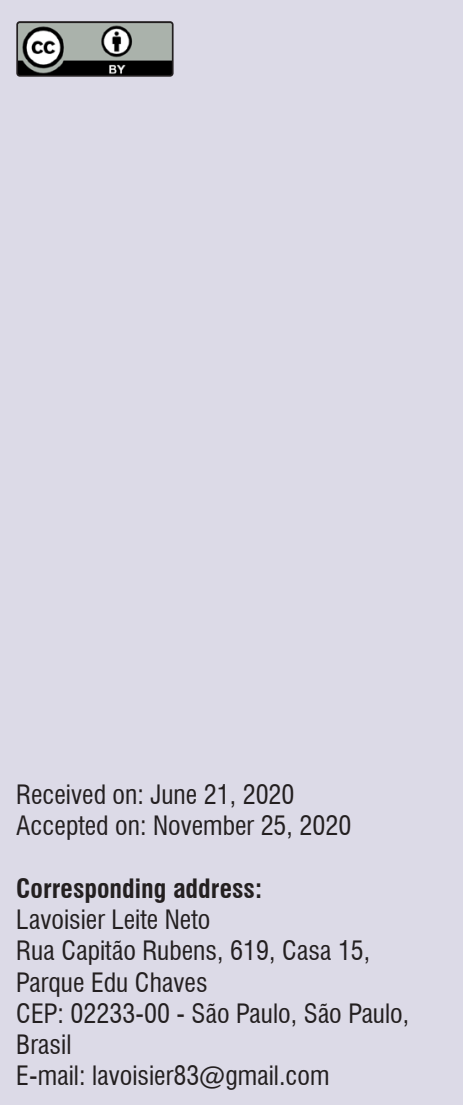

\section{ABSTRACT}

Purpose: to identify the knowledge produced in national and international researches on speech and language disorders in Amyotrophic Lateral Sclerosis, regarding the type of research and approach in different areas.

Methods: an integrative review performed on databases, using the following descriptors: Amyotrophic Lateral Sclerosis, Dysarthria, Language Disorders, Speech Production Measurement and Speech Disorders. The inclusion criteria covered articles that addressed motor speech and language disorders from 2013 to 2018, excluding duplications, and categorizing valid articles for analysis.

Results: 83 articles were selected, after screening the titles and abstracts. A large scientific production from different countries and areas, mainly Speech Therapy and Neurology, was found. Most of them was clinical research (65.06\%), with a main focus on speech motor disorders (42.16\%), speech and language motor disorders, cognition and behavior (27.71\%), and language disorders (12.06\%).

Conclusion: researches found were mostly clinical and aimed at determining the diagnosis of disorders in different areas of knowledge. With regard to communication, few studies have been found in Brazil, and international studies addressed high technology. The results confirmed the heterogeneous nature of the disease, which shows, in addition to motor impairment of speech, cognitive, behavioral and language impairments.

Keywords: Amyotrophic Lateral Sclerosis; Dysarthria; Language Disorders; Speech Production Measurement; Speech Disorders 


\section{INTRODUCTION}

Amyotrophic Lateral Sclerosis (ALS) is a heterogeneous neurodegenerative disease that results in disorders in the motor skills, cognition and behavior, highlighting serious problems in the individual's functional skills, thus, limiting his/her possibilities of social interaction ${ }^{1-3}$.

Speech motor disorders in individuals with ALS have been described over the years, with more intensity and frequency in those individuals who show bulbar onset symptoms ${ }^{2,4}$. They are present in more than $80 \%$ of the cases at some point of the disease, and $75-95 \%$ of patients lose their oral communication skills ${ }^{5}$.

Bulbar characteristics, in the speech motor decline, evidence the impairment of all of its subsystems, especially breathing, phonation, articulation and resonance ${ }^{2,6}$, and are noticed insofar as the intelligibility is reduced.

In advanced stages, it evolves with anarthria, which occurs approximately 18 months after the onset of bulbar disorders ${ }^{4}$, interfering with the individual's social interactions, even with family members and close friends, requiring alternative communication systems ${ }^{3}$ in order to keep the autonomy and life quality.

Although ALS is a neurodegenerative disease that specially affects the motor neurons, which determines the loss of functional capacity for daily and practical life activities $^{1}$, cognitive disorders are also present in $30 \%$ of the individuals, especially related to the executive function, and to the fluency, language and memory deficits. Approximately $10 \%$ of patients show frontotemporal dementia?

There is an increasing interest of researches on behavior disorders, social cognition and emotional aspects $^{8}$ related to a behavioral variant of the frontotemporal dysfunction ${ }^{9}$. In this regard, the multidisciplinary support is necessary to minimize the effects of the disease progression ${ }^{1,5,10}$.

Speech and language motor disorders in ALS put the patient in a situation of communication vulnerability, characterized by any failure in the communication process between the individual and their interlocutor, interfering with their social interactions, and possibly leading them to develop emotional problems and/ or anxiety, frustration, fear and sadness ${ }^{3}$, gradually moving them away from social interactions, family members and close friends.

Thus, communication vulnerability represents a major impact on the lives of people with ALS, justifying the focus of this review with respect to speech and language motor disorders.

Therefore, the purpose of this research was to identify the knowledge produced in national and international researches on speech and language disorders in ALS, regarding the type of research and approaches in different areas.

\section{METHODS}

This study used the method of integrative literature review, which has the aim to concisely systematize the knowledge already produced in the scientific community, to determine a panorama of the topic to be discussed, allowing the practice based on evidences ${ }^{11,12}$. To that end, six steps for integrative reviews $^{13}$ were followed, in order to facilitate the synthesis and analysis of eligible articles, and to minimize possible biases found, namely:

"1) Identification of the theme and selection of the research question; 2) Definition of inclusion and exclusion criteria; 3 ) Identification of pre-selected and selected studies; 4) Categorization of selected studies; 5) Analysis and interpretation of results; 6) Presentation of knowledge review/synthesis"13.

The guiding questions of this research were the following:

Which knowledge fields have been studying the ALS in relation to speech and language motor disorders? What is the analysis focuses and purposes of these studies in relation to such aspects? What is the panorama of Brazilian scientific production of this theme in relation to the international one?

The search was carried out in the research portals Biblioteca Virtual em Saúde (BVS) and Pubmed; as well as in Embase and Scopus databases. These databases were selected because they gather a vast material of publications in the health field, and for being the focus of search for most of health professionals. Considering the goals of this study, describers according to DeCS (Descritores de Ciências da Saúde), MeSH (Medical Subject Headings) and equivalent were used, as shown as follows:

\section{Amyotrophic Lateral Sclerosis [AND] \\ II. Dysarthria [OR] \\ III. Language Disorders [OR] \\ IV. Speech Production Measurement [OR] \\ V. Speech Disorders}

As research strategies, initially the describers and all their synonyms suggested in the databases were 
used in Portuguese, English and Spanish, and then criteria of inclusion were applied, namely: articles in Portuguese and English, published between 2013 and 2018, available in the selected databases.

After the survey, at first the articles titles and abstracts were analyzed, then those articles fulfilling the inclusion criteria were fully read. During the screening, those studies unrelated to dysarthria and language disorders, main focus of the study, were excluded, as well as those only addressing other pathologies not related to ALS.

After applying filters, 571 articles were found, of which 294 were excluded for being duplicated in the databases, and 194, after the titles and abstracts analysis, totalizing 83 valid articles for full reading, as described in Figure 1.

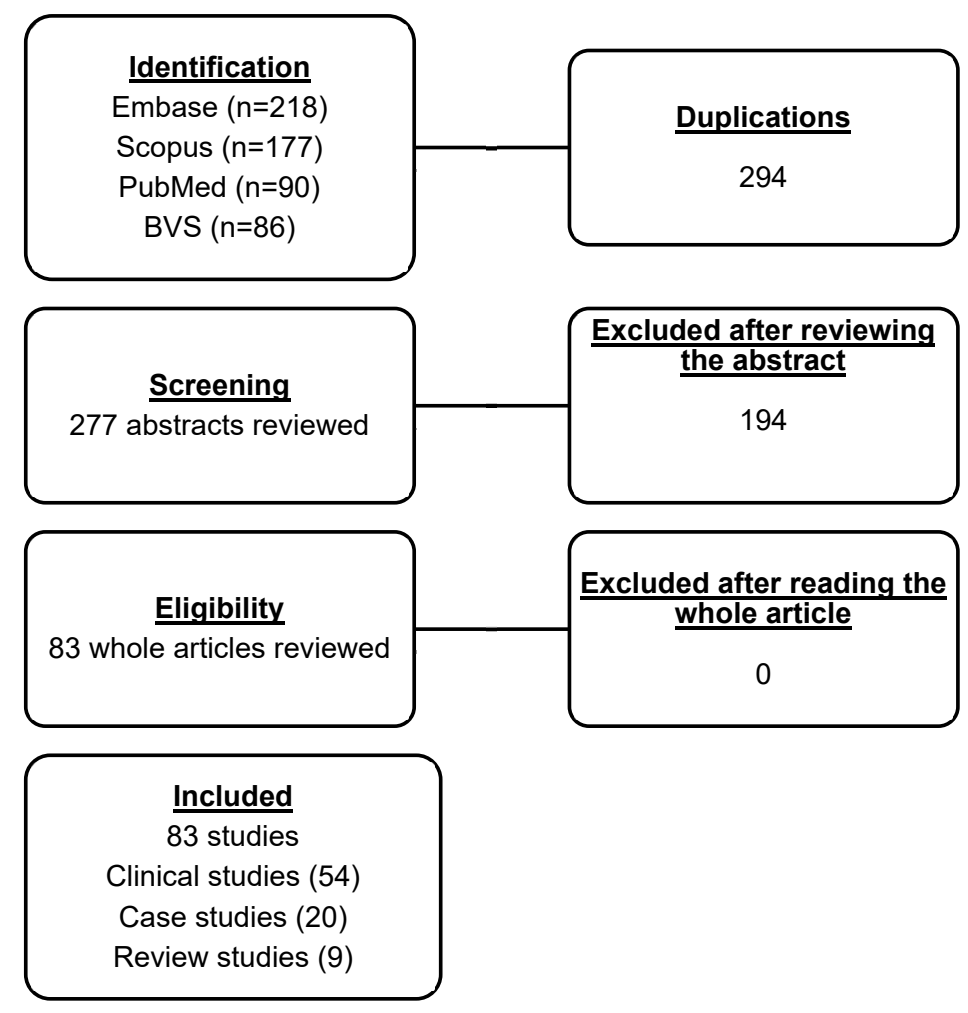

Figure 1. Flowchart of the survey, selection and analysis of articles

Selected studies were analyzed according to the criteria of an instrument, built and applied in another research ${ }^{14}$ (Annex 1), and for a better visualization and understanding, they were organized in tables, with absolute (n) and relative (\%) frequencies, and graphs.

Valid articles were distributed in three main categories, for subsequent analysis and discussion of results, as follows: (a) Type of research and knowledge field of the study; (b) Purpose and knowledge field of the study; (c) Study focus, subcategorized in (i) Speech motor disorders; (ii) Speech, language, cognition and behavior motor disorders; and (iii) Language disorders.

For the purpose of analysis, the area of each selected study was defined, according to the main author's department.

\section{LITERATURE REVIEW}

Articles addressing the studied theme were found in all selected databases after the application of filters, as presented in Table 1. 
Table 1. Distribution of articles according to the database

\begin{tabular}{lccc}
\hline \multirow{2}{*}{ Database } & Number of articles & After removing duplications & $\begin{array}{c}\text { After analyzing title and } \\
\text { abstract }\end{array}$ \\
\cline { 2 - 4 } & $\mathbf{N} / \%$ & $\mathbf{N} / \%$ & $\mathbf{N} / \%$ \\
\hline Embase & $218(38.17 \%)$ & $213(76.90 \%)$ & $55(66.27 \%)$ \\
BVS & $86(15.06 \%)$ & $12(4.33 \%)$ & $5(6.02 \%)$ \\
Scopus & $177(31.00 \%)$ & $23(8.30 \%)$ & $7(8.43 \%)$ \\
PubMed & $90(15.77 \%)$ & $29(10.45 \%)$ & $16(19.28 \%)$ \\
\hline Total & $571(100 \%)$ & $277(100 \%)$ & $83(100 \%)$ \\
\hline
\end{tabular}

Of the valid articles, 62.65\% (52) were clinical, non-experimental, researches, and $22.89 \%$ (19) were case studies, classified as having levels of evidence 4 and $5^{11}$, respectively. All the articles were available in international periodicals, with highlight to Amyotrophic Lateral Sclerosis and Frontotemporal Degeneration, corresponding to $15.66 \%$ (13) of all the analyzed publications, in addition to the Journal of Neurology, Neurosurgery, and Psychiatry - 6.02\% (5), followed by the Journal of Neurology; Journal of Speech, Language, and Hearing Research; Journal of Communication Disorders; Journal of Speech, Language, and Hearing Research, with three articles each.

We observed a vast production of studies on the theme, during the years of investigation, with researches from different areas of health, such as Biomedical and Linguistic Engineering, coming from different places, like the United States, Europe, Asia and South America, as shown in Figure 2.

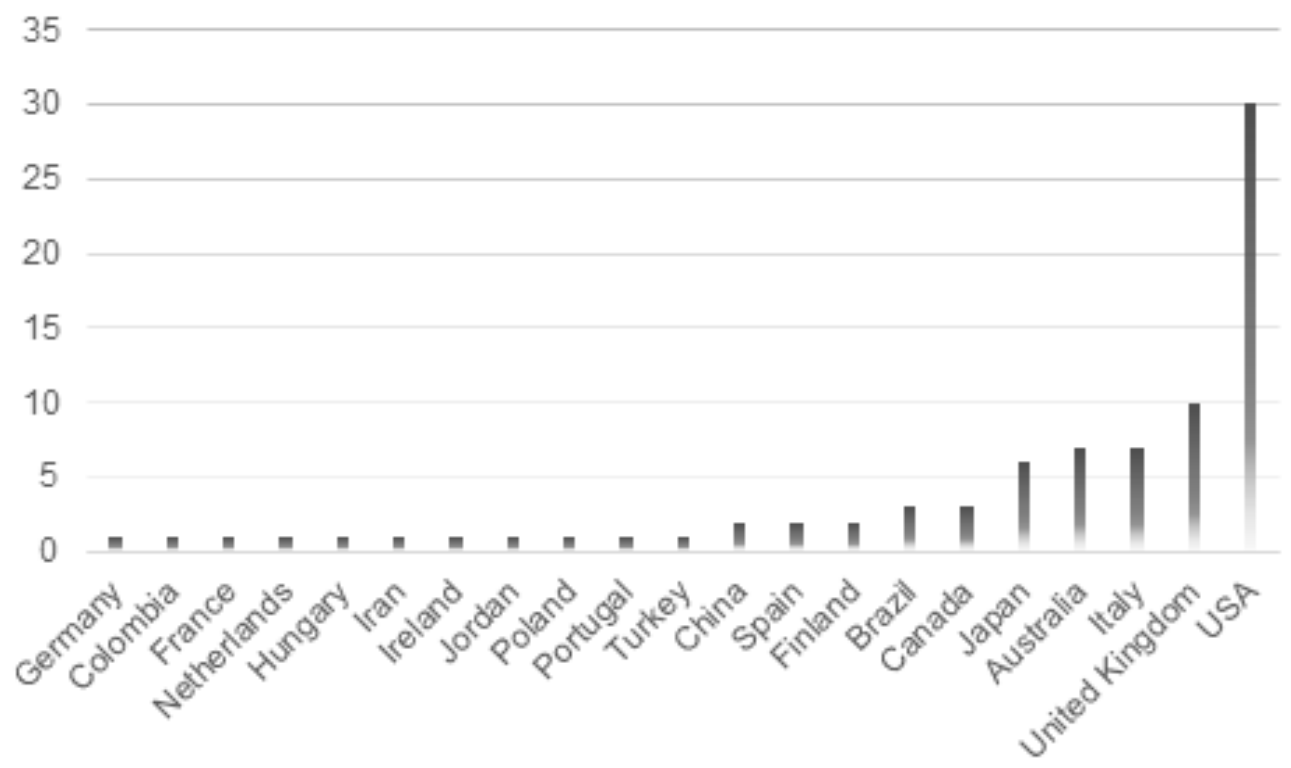

Figure 2. Distribution of articles according to the country of study 


\section{(a) Type of research and knowledge field of the study}

The large number of publications found shows the need of more knowledge about the fundamental physio pathological mechanisms underlying the disease, since they are still not well understood ${ }^{1}$. Among them, three studies from Brazilian southern and southeastern regions were found, and therefore we cannot say they represent the clinical profile of Brazilians with $\mathrm{ALS}^{15}$.

The different research fields found indicate the heterogeneous character of the disease, and stress the importance of a multidisciplinary care. A team comprised by caretakers, different health professionals, in addition to the medical doctor, such as: speech and language pathologist, physical therapist, occupational therapist, psychologist, including specialists in palliative care, allow maintaining the life quality of individuals until the late stages of the disease, where there is no more functional capacity for the performance of routine activities $^{2,10}$. However, most of the ALS population has no access to such services in a continued manner ${ }^{1}$, making it even more difficult for the patient and for the family to live with this disease.

The distribution of articles according to fields of knowledge and type of study conducted is detailed in Table 2.

Table 2. Distribution of articles according to area and type of study

\begin{tabular}{|c|c|c|c|c|}
\hline \multirow{2}{*}{ Area } & No. of Articles & Clinical Study & Case Study & Literature Review \\
\hline & $\mathrm{N} / \%$ & $\mathrm{~N} / \%$ & $\mathrm{~N} / \%$ & $\mathrm{~N} / \%$ \\
\hline Physiatry & $1(1.21 \%)$ & $1(1.92 \%)$ & $0(0.00 \%)$ & $0(0.00 \%)$ \\
\hline Odontology & $1(1.21 \%)$ & $1(1.92 \%)$ & $0(0.00 \%)$ & $0(0.00 \%)$ \\
\hline Occupational Therapy & $1(1.21 \%)$ & $1(1.92 \%)$ & $0(0.00 \%)$ & $0(0.00 \%)$ \\
\hline Otorhinolaryngology & $2(2.40 \%)$ & $1(1.92 \%)$ & $1(5.26 \%)$ & $0(0.00 \%)$ \\
\hline Linguistic & $3(3.62 \%)$ & $2(3.85 \%)$ & $0(0.00 \%)$ & $1(8.33 \%)$ \\
\hline Biomedical Engineering & $5(6.02 \%)$ & $1(1.92 \%)$ & $2(10.53 \%)$ & $2(16.67 \%)$ \\
\hline Neuropsychology & $5(6.02 \%)$ & $4(7.70)$ & $1(5.26 \%)$ & $0(0.00 \%)$ \\
\hline Psychology/Neuroscience & $10(12.05 \%)$ & 7 (13.46\%) & $1(5.26 \%)$ & $2(16.67 \%)$ \\
\hline Neurology & $27(32.53 \%)$ & $12(23.08 \%)$ & $11(57.90 \%)$ & $4(33.33 \%)$ \\
\hline Speech and Language Therapy & $28(33.73 \%)$ & $22(42.31 \%)$ & $3(15.79 \%)$ & $3(25 \%)$ \\
\hline Total & 83 (100\%) & 52 (100\%) & 19 (100\%) & $12(100 \%)$ \\
\hline
\end{tabular}

Results show a larger number of clinical researches (62.65\%), most of them cross-sectional (83.62\%), longitudinal $(14.46 \%)$, and only one (1.92\%) showing longitudinal and cross-sectional data. 32 (61.53\%) of them with a sample equal or smaller than 30 participants. It is known that when the study sample size is too restricted $(<30)$, statistical analyses might be impaired, which makes it difficult to obtain inferences that represent the target-population ${ }^{16}$.

The limited number of participants in the clinical and case studies also leads to question the difficulty to conduct researches with such a population. The explanation for that might be related to the limitations of the individual because of the disease evolution, with locomotion difficulty, geographic distances and emotional demands of availability and interest in participating in researches.

Specially in Brazil, we also consider the functioning problems of the Public Health System (SUS), which makes it difficult to obtain early diagnosis and does not facilitate referencing individuals with ALS to neurological centers ${ }^{15}$, as well as the limitations of the governmental incentive to the research developed in public universities.

\section{(b) Objectives of intervention and knowledge field of the study}

In Table 3, it is possible to observe the distribution of clinical study articles, according to their field and objective. 
Table 3. Distribution of articles according to field and objective of the study

\begin{tabular}{lcccc}
\hline \multirow{2}{*}{ Area } & No. of articles & Diagnosis & Rehabilitation/Care & $\begin{array}{c}\text { Alternative } \\
\text { Communication } \\
\text { Resources }\end{array}$ \\
\cline { 2 - 5 } & $\mathbf{N} / \%$ & $\mathbf{N} / \%$ & $\mathbf{N} / \%$ & $\mathbf{N} / \%$ \\
\hline Physiatry & $1(1.92 \%)$ & $0(0.00 \%)$ & $0(0.00 \%)$ & $1(14.28 \%)$ \\
Odontology & $1(1.92 \%)$ & $1(2.27 \%)$ & $0(0.00 \%)$ & $0(0.00 \%)$ \\
Occupational Therapy & $1(1.92 \%)$ & $0(0.00 \%)$ & $0(0.00 \%)$ & $1(14.28 \%)$ \\
Otorhinolaryngology & $1(1.92 \%)$ & $1(2.27 \%)$ & $0(0.00 \%)$ & $0(0.00 \%)$ \\
Linguistic & $2(3.85 \%)$ & $2(4.54 \%)$ & $0(0.00 \%)$ & $0(0.00 \%)$ \\
Biomedical Engineering & $1(1.92 \%)$ & $0(0.00 \%)$ & $0(0.00 \%)$ & $1(14.28 \%)$ \\
Neuropsychology & $4(7.69 \%)$ & $3(6.82 \%)$ & $0(0.00 \%)$ & $1(14.28 \%)$ \\
Psychology/Neuroscience & $7(13.47 \%)$ & $7(15.91 \%)$ & $0(0.00 \%)$ & $0(0.00 \%)$ \\
Neurology & $12(23.08 \%)$ & $11(25.00 \%)$ & $0(0.00 \%)$ & $1(14.28 \%)$ \\
Speech and Language Therapy & $22(42.31 \%)$ & $19(43.19)$ & $1(100 \%)$ & $2(28.55 \%)$ \\
\hline Total & $52(100 \%)$ & $44(100 \%)$ & $1(100 \%)$ & $7(100 \%)$ \\
\hline
\end{tabular}

Out of the 52 clinical studies, $84.61 \%$ had the aim of determining the diagnosis, using neuroimaging ${ }^{17}$, electromagnetic articulography ${ }^{18}$, ultrasound ${ }^{19}$, electromyography ${ }^{20}$, as well as subjective instruments of speech $^{21}$ and voice ${ }^{22}$ evaluation. These finds point out to an effort to understand altered parameters of the disease, possibly in order to define disease mechanisms, which can benefit from drug segmentation and therapeutic intervention, as well as to determine those patients who will respond to these therapeutic agents ${ }^{1}$.

On the other hand, a reduced number of researches has focused on the possibilities of care to such a population, and only one study had the aim to evaluate the impact of therapeutic solutions on the life quality of people with $\mathrm{ALS}^{23}$. Such a research panorama can interfere with the care offered to this public, and consequently with their well-being and life quality. As far as speech is concerned, therapeutic intervention is regarded as more effective in the early stages, and therefore can contribute to retard the decline of inteligibility ${ }^{24}$, although it cannot prevent the loss of this function with the disease progress.

Furthermore, another research, considering that dysarthria negatively impacts the communication functionality and social interactions of people with ALS, has investigated the impact of speech-focused intervention and the use of Augmentative and/or Alternative Communication Systems (AACS), concluding that such systems more expressively contribute to improve or at least stabilize the life quality and mood of this population, in detriment of speech-focused intervention, and therefore AACS should be offered as early as possible ${ }^{23}$.

Particularly in developed countries, there is an interest in researches with communication devices of high technology. Seven articles related the use of alternative communication resources, all of them high-tech, such as the Brain Computer Interface $(\mathrm{BCl})^{25}$ and the Eye Tracking Communication Devices (ETCDs ${ }^{26}$, to positive results, especially in the advanced stages of ALS.

In addition to these studies, others were found about the use of palatal lift prosthesis ${ }^{27}$ to improve the dysarthric pattern, which improved the sequential movement rate, speech rate, vital capacity, sound pressure level, intelligibility and reduction of nasality in the studied individuals with ALS; and mouth micro-switch ${ }^{21}$, that showed to be more agile when compared to the optical micro-switch actuated by means of head movement.

With the disease progress and anarthria acceleration, the use of Augmentative and/or Alternative Communication (AAC) systems and devices becomes necessary to make communication and interaction easier. We have found researches, specially from other countries, related to the use of eye control resources with computer interface, because of the loss of voluntary muscular control ${ }^{3}$, restricting the autonomy. At this point, when conventional AAC devices are not sufficient $^{3}$ high-tech resources are the most viable strategies to keep and restore the possibility of communication with family members, close friends and health team, positively affecting the life quality and emotional 
state of people ${ }^{23}$, and this is possibly one of the motivations for the researches with this focus.

However, it is noteworthy that the use of those resources, especially the high-tech ones, despite being offered in the marketplace, are not affordable to most of the people, especially in Brazil, because of countless difficulties, mainly economic difficulties and the lack of investment and development of public policies that make them affordable, as well as the reduced number of qualified and specialized professionals to make use of this kind of support ${ }^{28}$.

Results related to the effective use of AACS highlight the discussion about the focus of therapeutic interventions in ALS, in fields such as Speech and Language Therapy and Occupational Therapy, for instance. This finding is an important contribution of this article, corroborating a study indicating that most of patients describes a positive impact of communication devices in their life quality, also evidencing mood improvement and stabilization, making them necessary since the onset of the disease ${ }^{23}$.

The findings point to an urgent need to debate the communication vulnerability and AACS demands and applicability in ALS, which can contribute to foment public policies aiming to provide access of users in the public health system to this kind of technology, allowing a better care to this population.

\section{(c) Focus of the Study}

Figure 3 shows the results related to the study focus, subcategorized in speech motor disorders (42.16\%), followed by motor disorders of speech and language, cognition and behavior (27.71\%), and language disorders (12.06\%).

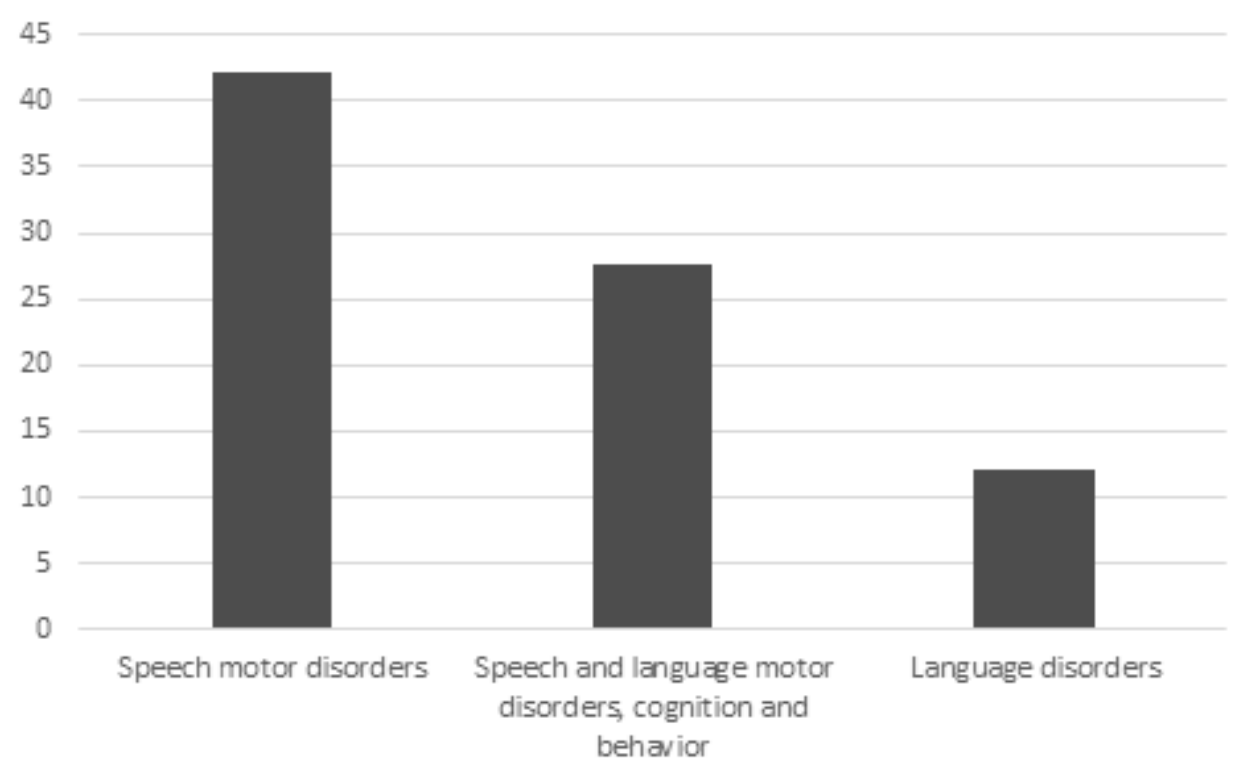

Figure 3. Distribution of articles according to study focus

Results related to the defined subcategories are shown as follows:

\section{(i) Speech motor disorders}

Dysarthria in patients with ALS is frequently characterized by articulatory imprecision, slow and laborious speech, accentuated hyper-nasality and vocal disorders such as hoarseness, roughness and breathiness ${ }^{22}$.
Speech-related articles found reveal a tendency to explore articulatory kinematic and intelligibility aspects, in order to identify the most common disorder patterns and to understand how long it takes to the individual with the disease to becomes incapable of oral communication.

Longitudinal study points out the loss of speech skills in $60 \%$ of the participants during the 2-year follow-up, although in such individuals' speech as well as functional communication remained adequate for 
18 months in average after the onset of the first bulbar symptoms ${ }^{4}$.

However, individuals with bulbar onset ALS lose the speech skills in average seven months after the first speech and language therapy intervention, which results in a limited time to them to adapt to an appropriate AAC resource. On the other hand, persons with spinal onset ALS, since they are already followed up because of other symptoms, are referred to the speech and language pathologist earlier and have more time for that adaptation ${ }^{4}$, increasing the chances of maintaining communication even in advanced stages of the disease.

In addition to that, some indicators showed to be sensible to the early bulbar decline, such as the articulatory and phonatory dysfunction, which are altered even before the deterioration of the speech intelligibility and the substantial reduction of the speech rate ${ }^{6}$.

According to some authors, the speech rate reduction to 120 words per minute (WPM) marks the beginning of the fast decline of intelligibility in oral communication $^{29}$. In this regard, since ALS patients start to have difficulties to be understood, they constantly need to repeat the words and phrases, and thus decide to avoid communicating with others ${ }^{2}$. This situation evidences the experienced vulnerability and implies restrictions in the communicative participation, throughout the course of the disease, caused by the difficulty in performing tasks, and because of the negative feelings involved in each experience ${ }^{10}$.

In general, we observe a constancy in the use of instruments and objective measures ${ }^{6}$ to evaluate the characteristics and seriousness of dysarthria in such individuals, such as the software Phonatory Aerodynamic System (PAS) (KayPentax, USA), used to evaluate the respiratory sub-system and that allows measuring eight speech measurements, pause patterns and two sub-glottal pressure measurements; the Multidimensional Voice Profile (MDVP, Model 5105) and PRAAT ${ }^{29}$ for the acoustic evaluation of voice and speech; devices to identify articulatory movements; nasometer for the test of the velopharyngeal function effectiveness; and also intelligibility measuring instruments, such as the Sentence Intelligibility Test (SIT) ${ }^{30}$.

In view of such findings, the speech evaluation by the speech and language pathologist is very important, being part of the differential diagnosis, indicating the onset of bulbar disorders and facilitating the intervention as early as possible.

\section{(ii) Motor disorders of speech and language, cognition and behavior}

Several studies of speech and language motor disorders found have their focus associated to cognition and behavior disorders, generally related to frontotemporal dysfunction found in 50 to $60 \%$ of ALS population, even without the presence of the genetic component, and which can show dementia, cognitive and behavior disorders, as well as social cognition and language deficits ${ }^{31}$.

Through an international consensus, criteria were developed to help differentiating and diagnosing such condition that take into consideration clinical, electrophysiological, neuropsychological, genetic and neuropathological aspects. It recognizes that ALS can be a pure syndrome or coexist with a Frontotemporal Dementia (ALS-FTD) ${ }^{9}$, and refers to the behavioral and/ or cognitive variant as the two mains clinical profiles of non-motor manifestations in not demented patients with $\mathrm{ALS}^{32}$.

The Frontotemporal Dementia (FTD) is present in approximately $15 \%$ of the individuals, and is usually found as a behavior variant, which is characterized for being an progressive syndrome that leads to an disorder in the interpersonal conduct regulation and emotional dullness, and which can be described by caretakers as uncommon irritability, selfishness or lack of interest ${ }^{9}$.

Cognitive disorders in ALS consist of fluency, language, social cognition, executive functions and verbal memory deficits ${ }^{7}$. In turn, behavioral disorders most common in ALS include apathy, disinhibition and irritability, and in a lower degree, abnormal eating habits, stereotyped behaviors, as well as sensorial abnormalities ${ }^{33}$. Apathy is the behavior most frequently identified, being detected in as much as $70 \%$ of the patients $8,9,32$.

In a clinical study, authors observed, after the neuropsychological evaluation, that $12 \%$ of the sample had FTD, and $64 \%$ showed some degree of cognitive and/ or behavioral impairment (including dementia). The cognitive domains most commonly affected were: executive function $(60 \%)$, verbal or visual memory $(35 \%)$ and verbal fluency (31\%). The most common psycho-behavioral symptoms were: irritability (40\%), impatience (30\%), depression (24\%), apathy $(12 \%)$ and disinhibition (10\%). Emotional lability was observed in $58 \%$ of the cases ${ }^{7}$.

Depression can be a psycho-behavioral symptom associated to ALS, and when present it interferes with 
the cognitive performance ${ }^{34}$, although it is not intensely described in the scientific literature ${ }^{33}$. Depression tends to be observed in the early phase of the disease, close to the diagnosis and frequently associated to caretakers also having the same symptom ${ }^{31}$.

It is noteworthy that such disorders can be present before the occurrence of motor manifestations, and once the ALS-FTD and/or disorder of the executive function is diagnosed, the prognosis is worse in comparison to those having it in its pure form, with the reduction of the survival by one year ${ }^{31}$.

\section{(iii) Language disorders}

Cognitive disorders in ALS have been intensely described in the scientific literature in the past few years, mainly related to the impairment of the executive function, although it is known that they are not restricted to this domain and can also represent the deterioration of language skills.

Some authors say that the cognitive impairment profile in ALS has a heterogeneous nature, with some patients showing disorders predominantly in the executive function, while others have it exclusively in language or a mixed pattern ${ }^{8}$. It is still unknown the reason why such domains are affected, however language processing aspects have been related to the frontal pathology in $\mathrm{ALS}^{34}$.

A study performed with 241 individuals, of which 185 with the behavioral variant and 56 with ALS-FTD, evidences that behavioral and affective changes are more frequent in the first group, while language deficiencies were more common in the second group. The impairment of the executive function equally occurs in both groups ${ }^{8}$. According to the same research, language disorders more frequently found are anomy, difficulty in finding words during conversation, echolalia, verbal perseveration, repetition of words and phrases, phonological disorders, agrammatism (in spontaneous speech or written), impaired comprehension, superficial dyslexia and orthographic deficiency ${ }^{8}$.

Other studies mention semantic impairment ${ }^{35}$, syntactic processing deficits ${ }^{34}$, difficulties in organizing narrative discourse ${ }^{36}$, aphasia ${ }^{37}$ and agraphia ${ }^{38}$.

\section{Limitation of the Study}

According to the survey data, most of the studies reviewed in this research has a limited sampling number, and therefore does not show a good degree of external generality. Therefore, a future systematic validation is necessary, with larger samples, in order to get a deeper knowledge of speech and language motor disorders in people with ALS, especially regarding the possibilities of available therapeutics, and thus allowing a more assertive therapeutic conduction.

Another important topic to be considered is the limited number of national researches, which makes it impossible to obtain epidemiological data representing the Brazilian population, as well as therapeutic resources more consistent with Brazilian socioeconomic reality.

\section{CONCLUSION}

A large scientific production related to speech and language motor disorders was found, with studies coming from different countries and various fields of knowledge, especially Neurology and Speech and Language Therapy. A reduced number of national researches was found, as compared to the international researches, which allows us to infer that issues related to the development of public policies, incentive to the research production, in addition to sociodemographic characteristics of the Brazilian population, as well as their difficult access to public services, can interfere with this matter.

Results confirm the heterogeneous nature of ALS that evidences, in addition to motor disorders, cognitive, behavioral and language impairments. Such findings stress the need of a multidisciplinary care, starting from the diagnosis, which should be intensified with the progress of the disease to provide life quality to the studied population, considering the few possibilities offered in therapeutic interventions.

Most of the researches aimed to diagnose disorders, in order to understand the disease itself and its underlying mechanisms.0\} To that end, the use of instruments and more objective measurements, in detriment of subjective evaluations with the use of perceptual parameters, were constant, indicating this trend of the studies in the field.

Motor disorders of speech were the predominant analysis focus, evidencing speech intelligibility as the main concern because of the disease evolution to dysarthria and anarthria. There was also a major interest of researchers in the cognitive and behavioral disorders present in the ALS, associated or not to dementia.

Another important finding is the lack of researches addressing efficient care and therapeutic resources to assist ALS population, which were restricted to the use of high-tech communication devices (brain-computer 
interface), especially in developed countries, however, distant from the Brazilian reality.

In view of this panorama, we reaffirm the importance of findings related to the communication vulnerability in ALS and to the need to foment studies on therapeutic intervention in such population, and thus, providing them with better quality of life, as well as communication and social participation. Also, in this sense, the work of a speech and language pathologist is extremely important, since the initial evaluation, to allow the observation of existing disorders, also contributing to the differential diagnosis, and allowing an intervention as early as possible.

On this path, findings more precisely highlight the scientific evidences of the theme, in order to guide the clinical practice of the speech and language pathologist and of other professionals alike, and to raise the interest in the still little explored fields of research, allowing a better care to such a population, this being, therefore, the major contribution of this article.

\section{REFERENCES}

1. Hardiman O, Al-Chalabi A, Chio A, Corr EM, Logroscino G, Robberecht W et al. Amyotrophic Lateral Sclerosis. Nat Rev Dis Primers. 2017;3:17071. doi: 10.1038/nrdp.2017.71.

2. Leite Neto L, Constantini AC. Dysarthria and quality of life in patients with Amyotrophic Lateral Sclerosis. Rev. CEFAC [Internet]. 2017 Sep [cited 2020 June 18];19(5):664-73. Available from: http://www.scielo. $\mathrm{br} /$ scielo.php?script $=$ sci_arttext\&pid $=$ S151618462017000500664\&lng=en. doi: https://doi. org/10.1590/1982-021620171954017

3. Leite Neto L, Constantini AC, Chun RYS. Communication vulnerable in patients with Amyotrophic Lateral Sclerosis: a systematic review. NeuroRehabilitation. 2017;40(4):561-8. doi: 10.3233/NRE-171443

4. Makkonen $\mathrm{T}$, Ruottinen $\mathrm{H}$, Puhto $\mathrm{R}$, Helminen $\mathrm{M}$, Palmio J. Speech deterioration in Amyotrophic Lateral Sclerosis (ALS) after manifestation of bulbar symptoms. Int $\mathrm{J}$ Lang Commun Disord. 2018;53(2):385-92. doi: 10.1111/1460-6984.12357

5. Felgoise SH, Zaccheo V, Duff J, Simmons Z. Verbal communication impacts quality of life in patients with Amyotrophic Lateral Sclerosis. Amyotroph Lateral Scler Frontotemporal Degener. 2016;17(34):179-83. doi: 10.3109/21678421.2015.1125499
6. Rong P, Yunusova Y, Wang J, Zinman L, Pattee GL, Berry JD et al. Predicting speech intelligibility decline in Amyotrophic Lateral Sclerosis based on the deterioration of individual speech subsystems. PLoS One. 2016;11(5):e0154971. doi:10.1371/ journal.pone.0154971

7. Branco LM, Zanao T, Rezende TJ, Casseb RF, Balthazar MF, Woolley SC et al. Transcultural validation of the ALS-CBS Cognitive Section for the Brazilian population. Amyotroph Lateral Scler Frontotemporal Degener. 2017;18(1-2):60-7. doi: 10.1080/21678421.2016.1211147

8. Goldstein LH, Abrahams S. Changes in cognition and behaviour in Amyotrophic Lateral Sclerosis: nature of impairment and implications for assessment. Lancet Neurol. 2013;12(4):368-80. doi: 10.1016/S1474-4422(13)70026-7

9. Strong MJ, Abrahams S, Goldstein LH, Woolley S, McLaughlin P, Snowden J et al. Amyotrophic Lateral Sclerosis - frontotemporal spectrum disorder (ALS-FTSD): revised diagnostic criteria. Amyotroph Lateral Scler Frontotemporal Degener. 2017;18(34):153-74. doi: 10.1080/21678421.2016.1267768

10. Baylor C, Burns M, Eadie T, Britton D, Yorkston K. A qualitative study of interference with communicative participation across communication disorders in adults. Am J Speech Lang Pathol. 2011;20(4):269-87. doi: 10.1044/1058-0360(2011/10-0084

11. de Souza MT, da Silva MD, de Carvalho R. Revisão integrativa: o que é e como fazer. Einstein. 2010;8(1):102-6. doi: https://doi.org/10.1590/ s1679-45082010rw1134

12. Fontanesi SRO, Schmidt A. Interventions in aphasia: an integrative review. Rev. CEFAC. 2016;18(1):252-62. doi: https://doi. org/10.1590/1982-021620161817715

13. Grupo Ănima Educação. Manual de revisão bibliográfica sistemática integrativa: a pesquisa baseada em evidências. Belo Horizonte: Grupo Ănima Educação; 2014 [Acesso em 19/05/2020]. Disponível em: http://biblioteca.cofen.gov.br/ wp-content/uploads/2019/06/manual_revisao_ bibliografica-sistematica-integrativa.pdf.

14. Ursi ES. Prevenção de lesões de pele no perioperatório: revisão integrativa da literatura [dissertação]. Ribeirão Preto (SP): Universidade de São Paulo, Escola de Enfermagem de Ribeirão Preto; 2005. 
15. Prado LGR, Bicalho ICS, Vidigal-Lopes M, Ferreira CJA, Mageste Barbosa LS, Gomez RS et al. Amyotrophic Lateral Sclerosis in Brazil: case series and review of the Brazilian literature. Amyotroph Lateral Scler Frontotemporal Degener. 2016;17(34):282-8. doi: 10.3109/21678421.2016.1143011

16. Miot HA. Tamanho da amostra em estudos clínicos e experimentais. J. Vasc. Bras. 2011;10(4):275-8. doi: http://dx.doi.org/10.1590/ S1677-54492011000400001

17. de Marco M, Merico A, Berta G, Segato N, Citton V, Baglione $A$ et al. Morphometric correlates of dysarthric deficit in Amyotrophic Lateral Sclerosis. Amyotroph Lateral Scler Frontotemporal Degener. 2015;16(7-8):464-72. doi: 10.3109/21678421.2015.1056191

18. Lee J, Littlejohn MA, Simmons Z. Acoustic and tongue kinematic vowel space in speakers with and without dysarthria. Int $\mathrm{J}$ Speech Lang Pathol. 2017;19(2):195-204. doi: 10.1080/17549507.2016.1193899

19. Noto YI, Simon N, Shibuya K, Matamala JM, Dharmadasa T, Kiernan MC. Dynamic muscle ultrasound identifies upper motor neuron involvement in Amyotrophic Lateral Sclerosis. Amyotroph Lateral Scler Frontotemporal Degener. 2017;18(5-6):404-10. doi: 10.1080/21678421.2017.1286355

20. Toro J, Reyes S. Tongue fasciculations in Amyotrophic Lateral Sclerosis. N Engl J Med. 2014;371(5):e7. doi: 10.1056/NEJMicm1309849

21. Searl J, Knollhoff $S$. Changes in lingual-alveolar contact pressure during speech over six months in Amyotrophic Lateral Sclerosis. J. Commun. Disord. 2017;70:49-60. doi: 10.1016/j.jcomdis.2017.10.004

22. Tomik J, Tomik B, Wiatr M, Składzień J, Stręk P, Szczudlik $A$. The evaluation of abnormal voice qualities in patients with Amyotrophic Lateral Sclerosis. Neurodegener Dis. 2015;15(4):225-32. doi: 10.1159/000381956

23. Körner S, Siniawski M, Kollewe K, Rath KJ, Krampfl K, Zapf $A$ et al. Speech therapy and communication device: impact on quality of life and mood in patients with Amyotrophic Lateral Sclerosis. Amyotroph Lateral Scler Frontotemporal Degener. 2013;14(1):20-5. doi: 10.3109/17482968.2012.692382
24. Wang J, Kothalkar PV, Kim M, Yunusova $Y$, Campbell TF, Heitzman D et al. Predicting Intelligible Speaking Rate in individuals with Amyotrophic Lateral Sclerosis from a small number of speech acoustic and articulatory samples. Workshop Speech Lang Process Assist Technol. 2016;2016:91-7. doi: 10.21437/SLPAT.2016-16

25. Guy V, Soriani MH, Bruno M, Papadopoulo T, Desnuelle C, Clerc M. Brain computer interface with the P300 speller: usability for disabled people with Amyotrophic Lateral Sclerosis. Ann Phys Rehabil Med.. 2018;61(1):5-11. doi: 10.1016/j. rehab.2017.09.004

26. Caligari M, Godi M, Guglielmetti S, Franchignoni F, Nardone A. Eye tracking communication devices in Amyotrophic Lateral Sclerosis: impact on disability and quality of life. Amyotroph Lateral Scler Frontotemporal Degener. 2013;14(7-8):546-52. doi: 10.3109/21678421.2013.803576

27. Alfwaress FS, Bibars AR, Hamasha A, Maaitah EA. Outcomes of palatal lift prosthesis on dysarthric speech. J Craniofac Surg. 2017;28(1):30-5. doi: 10.1097/SCS.0000000000003167

28. Pelosi M. Dispositivos móveis para comunicação alternativa: primeiros passos. In: Passerino L, Bez MR, Pereira ACC, Peres A (orgs). Comunicar para Incluir. Porto Alegre: CRBF, editor. 2013. p. 371-80.

29. Rong P, Yunusova Y, Wang J, Green JR. Predicting early bulbar decline in Amyotrophic Lateral Sclerosis: a speech subsystem approach. Behav Neurol. 2015;2015:183027. doi: https://doi. org/10.1155/2015/183027

30. Beukelman D, Yorkston K, Hakel M, Dorsey M. Speech Intelligibility Test (SIT) [Computer Sofware]. Neb, USA: Madonna Rehabilitation Hospital, Lincoln, 2007.

31. Woolley SC, Strong MJ. Frontotemporal dysfunction and dementia in Amyotrophic Lateral Sclerosis. Neurol Clin. 2015;33(4):787-805. doi: 10.1016/j. ncl.2015.07.011

32. Consonni M, Catricalà E, Dalla Bella E, Gessa VC, Lauria G, Cappa SF. Beyond the consensus criteria: multiple cognitive profiles in Amyotrophic Lateral Sclerosis. Cortex. 2016;81 (2016):162-7. doi: 10.1016/j.cortex.2016.04.014 
33. Van Der Hulst EJ, Bak TH, Abrahams S. Impaired affective and cognitive theory of mind and behavioural change in Amyotrophic Lateral Sclerosis. J Neurol Neurosurg Psychiatry. 2015;86(11):1208-15. doi: 10.1136/ jnnp-2014-309290

34. Tsermentseli S, Leigh PN, Taylor LJ, Radunovic A, Catani M, Goldstein LH. Syntactic processing as a marker for cognitive impairment in Amyotrophic Lateral Sclerosis. Amyotroph Lateral Scler Frontotemporal Degener. 2015;17(1-2):69-76. doi: 10.3109/21678421.2015.1071397

35. Leslie FV, Hsieh S, Caga J, Savage SA, Mioshi $E$, Hornberger $M$ et al. Semantic deficits in Amyotrophic Lateral Sclerosis. Amyotroph Lateral Scler Frontotemporal Degener. 2015;16(1-2):46-53. doi: $10.3109 / 21678421.2014 .987301$

36. Ash S, Olm C, McMillan CT, Boller A, Irwin DJ, McCluskey $L$ et al. Deficits in sentence expression in Amyotrophic Lateral Sclerosis. Amyotroph Lateral Scler Frontotemporal Degener. 2015;16(1-2):31-9. doi: $10.3109 / 21678421.2014 .974617$

37. Baumer D, Butterworth R, Menke RA, Talbot K, Hofer M, Turner MR. Progressive hemiparesis (Mills syndrome) with aphasia in Amyotrophic Lateral Sclerosis. Neurology. 2014;82(5):457-8. doi: 10.1212/WNL.0000000000000090

38. Maeda K, Shiraishi T, Idehara R. Agraphia in mobile text messages in a case of Amyotrophic Lateral Sclerosis with frontotemporal dementia. Intern Med. 2015;54(23):3065-8. doi: 10.2169/ internalmedicine.54.4982 


\section{ANNEX 1}

\section{Data collection instrument}

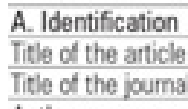

Authors

Name

Institution

Background

Country

Language

Year of publication

B. Institution holding the study

Haspital

University

Research center

Sole institution

Multicenter study

Other institutions

No identification of senting

C. Type of publication

Nursing publication

Medical publication

Publication in another area of health. Which area?

D. Methodological characteristics of the study

1. Type of publication

1.1 Research

() Quantitative approach

() Experimental design

() Quasi-experimental design

() Non-experimental design

() Qualitative approach

1.2 Non research

(1) Literature review

() Report of experience

() Others

2. Objective or investigation question

3. Sample

\subsection{Selection}

() Random

(1) Convenience

() Other

3.2 Size (n)

() Initial

() Final

3.3 Characteristics

Age

Sex: $M() F()$

Race

Diagnosis

Type of surgery

3.4 Inclusionvexclusion criteria of subjects

\section{Treatment of data}

5. Interventions performed
5.1 Independent variable

5.2 Dependent variable

5.3 Control group: yes (/) no ()

5.4 Measurement instrument: yes (] no ()

5.5 Duraticn of the study

5.6 Methods employed to measure the intervention

7.1 Statistical treatment

7.2 Significance level

8.1 The conclusions are justified based on the results

82 What are the recommendations of the authors?

\section{Evidence level}

E. Assessing methodological rigor

Clarity to identify the methodological steps in the text imethod

employed, participating subjects, inclusion/ exclusion criteria.

intervention, results)

Identification of restrictions or biases 